\title{
The weaver Mutation Reverses the Function of Dopamine and GABA in Mouse Dopaminergic Neurons
}

\author{
Ezia Guatteo, ${ }^{1}$ Francesca R. Fusco, ${ }^{1}$ Patrizia Giacomini, ${ }^{3}$ Giorgio Bernardi, ${ }^{1,2}$ and Nicola B. Mercuri ${ }^{1,2}$ \\ ${ }^{1}$ Fondazione Santa Lucia, Istituto di Ricovero e Cura a Carattere Scientifico, 00179 Rome, Italy, ${ }^{2}$ Clinica Neurologica, \\ Università di Tor Vergata, 00173 Rome, Italy, and ${ }^{3}$ Clinica Neurologica, Università di Roma La Sapienza, 00161 Rome, Italy
}

In the present study, we characterized the intrinsic electrophysiological properties and the membrane currents activated by dopamine (DA) $D_{2}$ and $\mathrm{GABA}_{\mathrm{B}}$ receptors in midbrain dopaminergic neurons, maintained in vitro in a slice preparation, from wild-type and homozygous weaver (wv/wv) mice. By using patch-clamp techniques, we found that membrane potential, apparent input resistance, and spontaneous firing of $w V / W V$ dopaminergic neurons were similar to those of dopaminecontaining cells recorded from nonaffected $(+/+)$ animals.

More interestingly, the $w v / w v$ neurons were excited rather than inhibited by dopamine and the $\mathrm{GABA}_{\mathrm{B}}$ agonist baclofen. This neurotransmitter-mediated excitation was attributable to the ac- tivation of a G-protein-gated inward current that reversed polarity at a membrane potential of approximately $-30 \mathrm{mV}$. We suggest that the altered behavior of the receptor-operated $w v$ G-proteingated inwardly rectifying $\mathrm{K}^{+}$channel 2 (GIRK2) might be related to the selective degeneration of the dopaminergic neurons. In addition, the $w v$ GIRK2 would not only suppress the autoreceptor-mediated feedback inhibition of DA release but could also establish a feedforward mechanism of DA release in the terminal fields.

Key words: substantia nigra; dopamine; baclofen; inwardly rectifying $\mathrm{K}^{+}$channels; weaver mouse; electrophysiology; dopamine-related disorders
Weaver $(w v)$ is an autosomic recessive mutation of the mouse $\mathrm{G}$-protein-gated inwardly rectifying $\mathrm{K}^{+}$channels (GIRK2) mainly associated to postnatal loss of the external granuli of the cerebellum (Rakic et al., 1973) and the dopaminergic cells of the ventral midbrain (Schmidt et al., 1982; Gupta et al., 1987; Triarhou et al., 1988; Smith et al., 1990). With regard to the dopaminergic neurons, it has been shown that they degenerate during the first 3 weeks of life in homozygous $w v / w v$ mutant mice. However, the number of tyrosine hydroxylase $(\mathrm{TH})$-positive neurons in $w v / w v$ and wild-type $(+/+)$ midbrain is the same at birth (Bayer et al., 1995; Verney et al., 1995), suggesting that the $w v$ gene exclusively targets and impairs postmitotic dopaminergic cells. Consequently, the $w v / w v$ mouse has a lower level of dopamine (DA) in the brain than $+/+$ mice (Schmidt et al., 1982; Roffler-Tarlov and Graybiel, 1984; Triarhou et al., 1988) and represents a genetic animal model of nigrostriatal deficiency that could mimic the pathophysiology of Parkinson's disease (Simon and Ghetti, 1994).

The $w v$ mutation is a single amino acid substitution (glycine 156 to serine) located in the gene encoding for GIRK2 (Patil et al., 1995). The functional GIRK channel consists of tetramers of five subunits (Kofuji et al., 1996), and only the GIRK1-GIRK3 subunits were found in the CNS. The GIRK channel is the functional target of many neurotransmitters (North, 1989; Liao et al., 1996; Sodickson and Bean, 1998) and regulates neuronal excitability, being permeable to potassium ions (Hille, 1992; Jan and Jan, 1994). Western blotting, in situ hybridization, and immunocytochemistry studies have shown that a strong GIRK2 signal is present in the dopaminergic neurons of the substantia nigra and ventral tegmental area, being the GIRK1 at the background level (Liao et al., 1996; Murer et al., 1997; Inanobe et al., 1999). When expressed in Xenopus oocytes, the $w v$ GIRK2 displays three novel properties:

Received April 3, 2000; revised May 22, 2000; accepted May 25, 2000.

This work was supported by Telethon Grant E.747 to N.B.M. We thank Dr. Marco Molinari and Dr. Maria Teresa Viscomi for their advice in hystochemistry experiments, Dr. Nicola Berretta for help in the discussion, and Mauro Federici for technical assistance.

Correspondence should be addressed to Dr. Nicola B. Mercuri, Laboratory of Experimental Neurology, Fondazione Santa Lucia, Istituto di Ricorvero e Cura a Carattere Scientifico, Via Ardeatina 306, 00179 Rome, Italy. E-mail: mercurin@med.uniroma2.it.

Copyright (C) 2000 Society for Neuroscience $0270-6474 / 00 / 206013-08 \$ 15.00 / 0$
(1) a loss of selectivity for potassium ions and gain of permeability for sodium (Slesinger et al., 1996; Tong et al., 1996) and/or calcium (Silverman et al., 1996; Tucker et al., 1996); (2) a constitutive activation that does not require G-proteins (Navarro et al., 1996); and (3) a blockade by a class of molecules (QX-314, MK-801, verapamil) that do not affect the wild GIRK. Although there is general agreement on the loss of $\mathrm{K}^{+}$selectivity and on the pharmacology of the $w v$ GIRK2, the gating properties and functional effects on native neurons appear to be very heterogeneous depending on the type of neurons investigated. It is not yet known whether the constitutive activation of the inwardly rectifying $\mathrm{K}^{+}$channels is inherent to the mutated $w v$ GIRK2 channel protein or is an indirect consequence of other cellular properties (Silverman et al., 1996). For instance, the developmental stage of $w v / w v$ cerebellar granule cells determines the state of the G-protein modulation of the inwardly rectifying current and possibly its tonic activation (Kofuji et al., 1996; Slesinger et al., 1996, 1997; Surmeier et al., 1996; Rossi et al., 1998). On the other hand, the wv GIRK2 is neither tonically active nor G-protein-operated in CA3 hippocampal neurons (Jarolimek et al., 1998). Considering that GIRK2 tetramers are almost selectively present in the membrane of midbrain dopaminergic neurons in which they represent the common functional target of the inhibitory inputs mediated by dopamine $\mathrm{D}_{2}$ and $\mathrm{GABA}_{\mathrm{B}}$ receptors (Lacey et al., 1988; Kim et al., 1997; Inanobe et al., 1999), we have been interested in studying whether the $w v$ mutation affects the electrical membrane properties and the response to dopamine and GABA of these neurons recorded in slices of mouse mesencephalon.

\section{MATERIALS AND METHODS}

Preparation of the tissue. Homozygous $(w v / w v)$ weaver mice were obtained by breeding heterozygous $+/ w v$ mice (B6CBA) (Jackson Laboratories, Bar Harbor, ME). They were $\sim 25 \%$ of littermates according to simple mendelian segregation and were identified by their clearly visible motor dysfunction, tremor, and cerebellar atrophy (Rakic and Sidman, 1973). Horizontal slices comprising the substantia nigra and the ventral tegmental area were cut from the ventral mesencephalon of 16- to 20 -d-old $w v / w v$, and $+/+$ mice were anesthetized with ketamine and killed. The method used has been described previously (Mercuri et al., 1994, 1997). The brain was rapidly removed, and the slices (200- to 250 - $\mu$ m-thick) were obtained by using a vibratome starting from the ventral surface of the midbrain. Slices recovered for at least $1 \mathrm{hr}$ in a holding chamber and then were transferred into a recording chamber. They were completely submerged with a con- 


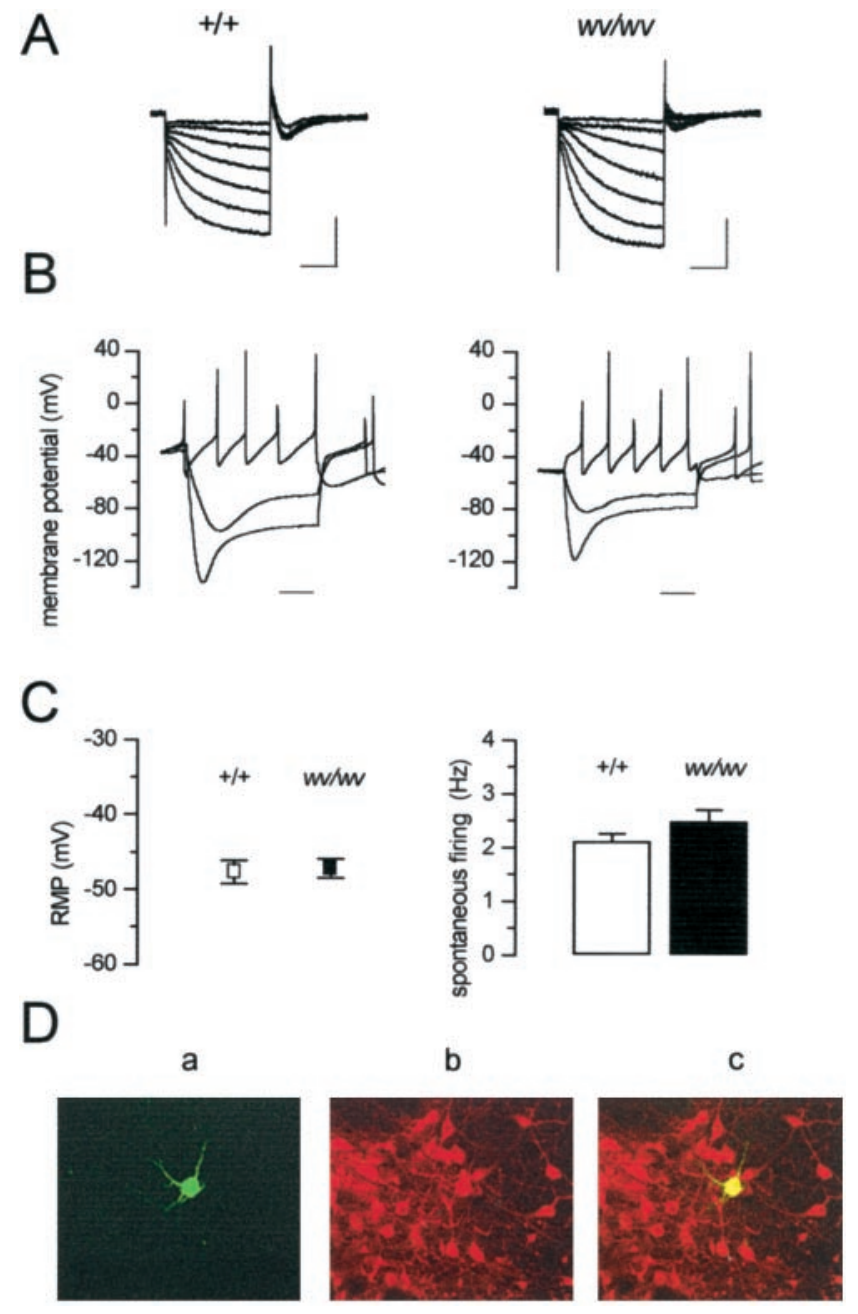

Figure 1. Electrophysiological and immunohistochemical identification of midbrain dopaminergic neurons in $+/+$ and $w v / w v$ mice. $A$, Hyperpolarizing voltage steps from -60 to $-120 \mathrm{mV}\left(10 \mathrm{mV}\right.$ increments, $V_{\mathrm{h}}$ of $\left.-40 \mathrm{mV}\right)$ activated the mixed cation current $\left(I_{\mathrm{h}}\right)$ in both genotypes. Calibration: 250 $\mathrm{msec}, 500 \mathrm{pA}$. $B$, The corresponding current-clamp recording showed that hyperpolarizing pulses $(-0.5$ and $-1 \mathrm{nA})$ activated the $I_{\mathrm{h}}$ current, thus producing a typical sag potential in both cells taken form the two genotypes. A depolarizing current pulse $(0.5 \mathrm{nA})$ elicited a pacemaker-like sequence of action potentials in both neurons. Action potential amplitudes are clipped because of low sampling rate of the digital interface. Time bar: $100 \mathrm{msec}$. $C$, Left, The white square indicates the mean resting membrane potential $(R M P)$ of $+/+$ dopaminergic cells $(-47.6 \pm 1.5 \mathrm{mV}, n=17)$, and the black square indicates the mean resting membrane potential of $w v / w v$ cells $(-47.1 \pm 1.3 \mathrm{mV}, n=18)$; values were not significantly different $(p=$ 0.81 ). Right, The columns indicate the mean spontaneous firing recorded in cell-attached configuration in $+/+($ white $)(2.1 \pm 0.12 \mathrm{~Hz}, n=7)$ and $w v / w v$ (black) $(2.4 \pm 0.2 \mathrm{~Hz}, n=15)$ neurons; values were not significantly different $(p=0.35)$. $D$, Confocal laser scanning microscope image of a $w v / w v$ neuron loaded with biocytin $(5 \mathrm{~mm})$ through the patch pipette showing typical features of a dopaminergic neuron (magnification, 20×): $a$, biocytin staining as revealed by FITC fluorescence; $b$, TH immunostaining as revealed by TRITC fluorescence (note that many neurons, including the recorded one, resulted in being TH-positive, within the SNc); $c$, merged image of the two fluorescent stainings.

tinuously flowing $(2.5 \mathrm{ml} / \mathrm{min})$ artificial CSF solution at $34-35^{\circ} \mathrm{C}$, $\mathrm{pH} 7.4$. This solution contained (in mM): $\mathrm{NaCl} 126, \mathrm{KCl} 2.5, \mathrm{MgCl}_{2} 1.2, \mathrm{NaH}_{2} \mathrm{PO}$ $1.2, \mathrm{CaCl}_{2} 2.4$, glucose $10, \mathrm{NaHCO}_{3} 18$, gassed with $95 \% \mathrm{O}_{2}$ and $5 \% \mathrm{CO}_{2}$, $\mathrm{pH} 7.4$.

Patch-clamp recordings. The recording chamber was mounted on the stage of an upright microscope (Axioscope FS; Zeiss, Oberkochen, Germany) equipped for an infrared video microscopy (Hamamatsu, Hamamatsu City, Japan). Individual dopaminergic neurons were visualized by infrared video imaging and approached by applying positive pressure. Pipettes were made from borosilicate glass $(1.5 \mathrm{~mm}$; World Precision Instruments, Sarasota, FL) and pulled with a vertical PP 83 Narishige (Tokyo, Japan) puller. They had a resistance of $\cong 4 \mathrm{M} \Omega$ when filled with a standard solution containing (in $\mathrm{mM}$ ): $\mathrm{K}^{+}$gluconate 145 ,
$\mathrm{CaCl}_{2}$ 0.1, $\mathrm{MgCl}_{2}$ 2, HEPES 10, EGTA 0.75, Mg-ATP 2, and $\mathrm{Na}_{3}$-GTP 0.3, $\mathrm{pH}$ 7.3. In a subset of experiments, $\mathrm{Na}_{3}$-GTP was substituted with the nonhydrolizable analog GTP- $\gamma-\mathrm{S}(0.6 \mathrm{mM})$ or with GDP- $\beta$-S $(0.6 \mathrm{~mm})$. Whole-cell recordings were performed with an Axopatch 1D amplifier (Axon Instruments, Foster City, CA) and series resistances were compensated. Hyperpolarizing voltage steps were delivered from -60 to $-120 \mathrm{mV}$ (holding potential of $-40 \mathrm{mV}, 10 \mathrm{mV}$ increments) and lasted $800 \mathrm{msec}$. Activation kinetics of $I_{\mathrm{h}}$ were calculated by fitting the current at $-120 \mathrm{mV}$ with a first-order exponential decay function.

Because of the presence of the large $I_{\mathrm{h}}$ current in the dopaminergic neurons (Grace and Onn, 1989; Lacey et al., 1989; Johnson and North, 1992; Mercuri et al., 1995, 1997), voltage ramps were preceded by a voltage step of $600 \mathrm{msec}$ from the holding potential of -40 to $-120 \mathrm{mV}$ to fully activate the $I_{\mathrm{h}}$ current (see Fig. $4 C$ ). The membrane voltage and current were acquired using pClamp and Axioscope softwares (Axon Instruments); data analysis was performed using Origin software (Microcal, Northampton, MA). Cell-attached recordings were made after the giga seal was established, by measuring the number of spontaneous action potentials from the extracellular side of the membrane.

Drug application. Drugs were bath-applied by switching the superfusing solution to one containing a known concentration of drugs. Full exchange of the solution in the recording chamber was achieved within 1 min. L-sulpiride was from Ravizza, CGP 55845A and R-baclofen were from Novartis Pharma Ag (Basel, Switzerland), QX-314 was purchased from Alomone Labs (Jerusalem, Israel), and ZD 7288 was from Tocris Cookson (Bristol, UK). Dopamine, GTP- $\gamma$-S, and GDP- $\beta$-S were from Sigma (Milano, Italy). In voltage-clamp, experiments we used higher DA concentration to evoke maximal current amplitudes.

Immunohystochemistry. Biocytin (free base, $5 \mathrm{~mm}$; Sigma) was added to
$+/+$

A
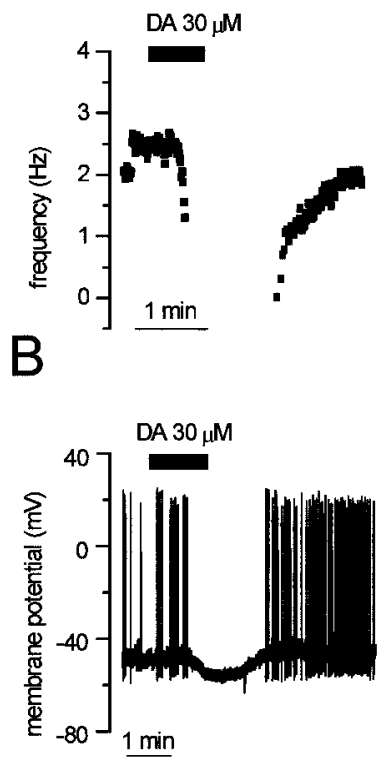

C

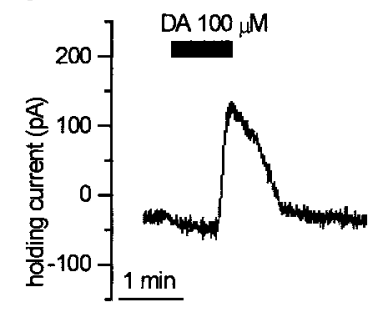

$w / W w$
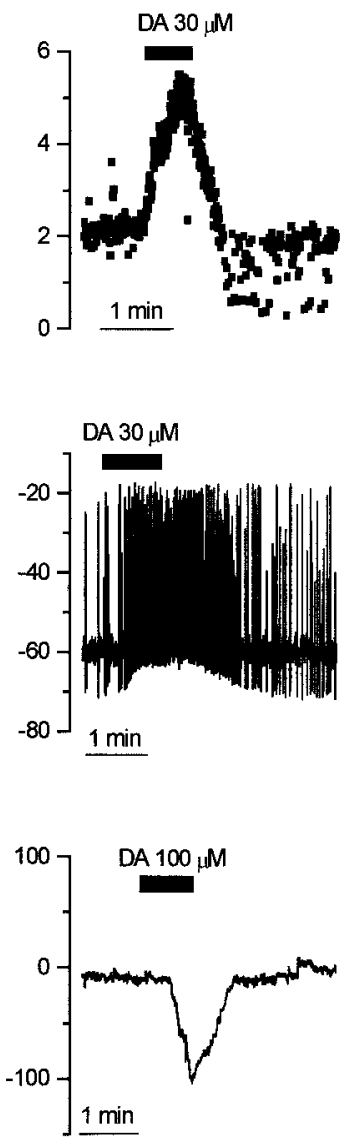

Figure 2. DA mediates inhibition of $+/+$ and excitation of $w v / w v$ neurons. $A$, Cell-attached recordings from a $+/+(l e f t)$ and $w v / w v(r i g h t)$ cell showing the changes of spontaneous firing during the extracellular application of DA $(30 \mu \mathrm{M})$. DA clearly inhibited the firing of the $+/+$ neuron, whereas it increased the activity of the $w v / w v$ neuron. $B$, Whole-cell current-clamp recordings of two dopaminergic cells in which DA caused membrane hyperpolarization-inhibition $(+/+)$ and depolarization-excitation $(w v /$ $w v)$. $C$, Voltage-clamp recordings (at $V_{\mathrm{h}}$ of $-40 \mathrm{mV}$ ) showing the activation of outward $(+/+)$ and inward $(w v / w v)$ currents caused by DA $(100 \mu \mathrm{M})$ in $+/+$ and $w v / w v$ dopaminergic cells, respectively. 
$+1+$

$w W / W$

A
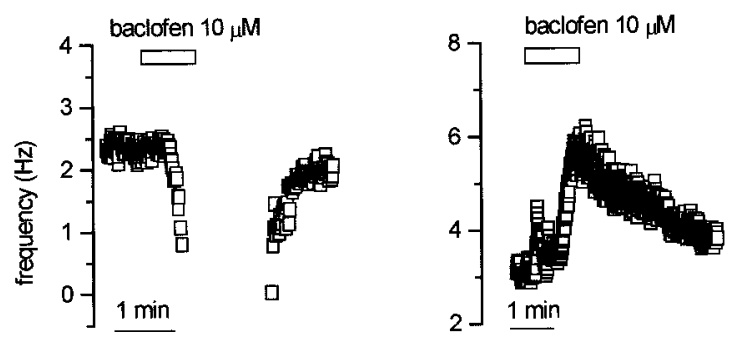

B
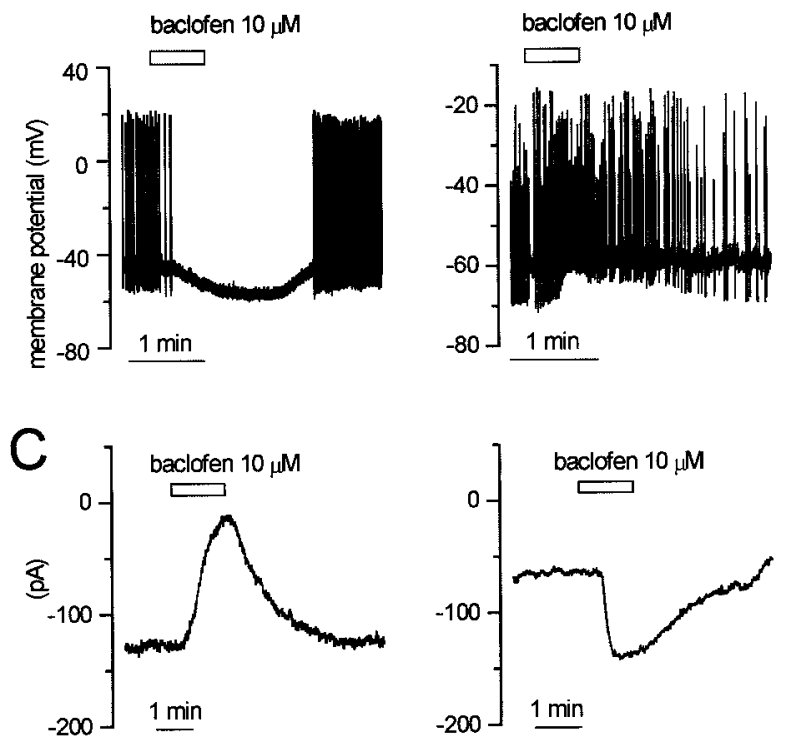

Figure 3. The $\mathrm{GABA}_{\mathrm{B}}$ agonist baclofen mediates inhibition of $+/+$ and excitation of $w v / w v$ neurons. $A$, Cell-attached recordings from a $+/+(l e f t)$ and a $w v / w v$ (right) neuron showing the modification of the spontaneous firing caused by the $\mathrm{GABA}_{\mathrm{B}}$ receptor agonist baclofen $(10 \mu \mathrm{M})$. Note the increase in firing frequency induced by this compound in the $w v / w v$ neuron. $B$, Whole-cell current-clamp recordings showing the modification in membrane potential and firing activity in $+/+$ and $w v / w v$ neurons. $C$, Corresponding voltage-clamp recordings (at $V_{\mathrm{h}}$ of $-40 \mathrm{mV}$ ) showing the changes in membrane current caused by baclofen in a $+/+$ versus a $w v / w v$ neuron. Note that, like dopamine, baclofen activated an inward rather than outward current in $w v / w v$ neurons.

the pipette solution to perform post hoc labeling of the recorded cells with $\mathrm{TH}$. Immediately after recording, slices containing biocytin-loaded cells were fixed by immersion in $4 \%$ paraformaldehyde in $0.1 \mathrm{M}$ PBS overnight at $+4^{\circ} \mathrm{C}$. The tissue was subsequently immersed in $20 \%$ sucrose $-10 \%$ glycerol in $0.1 \mathrm{M}$ PBS for $3 \mathrm{hr}$ at room temperature for cryoprotection. Slices were then frozen and cut to $40-\mu$ m-thick sections by a sliding microtome. Sections were incubated with a cocktail of avidin-conjugated fluorescein isothiocyanate (FITC) (1:200; Sigma) and anti-mouse tyrosine hydroxylase monoclonal antibody (1:200) in PBS containing $0.1 \%$ Triton $\mathrm{X}-100$ overnight at $+4^{\circ} \mathrm{C}$. After $10 \mathrm{~min}$ rinses in $0.1 \mathrm{M}$ PBS, sections were incubated in a mixture of avidin-conjugated FITC $(1: 200)$ and tetramethyl rhodamine (TRITC) (Sigma) -conjugated goat anti mouse IgG 1:50 in PBS containing $0.1 \%$ Triton $\mathrm{X}-100$ for $3 \mathrm{hr}$ at room temperature. Sections were then rinsed three times for $10 \mathrm{~min}$ in $0.1 \mathrm{M}$ PBS, mounted on slides, and coverslipped with $50 \%$ glycerol in PBS. Slides were observed with an epi-illumination fluorescence microscope (Zeiss) and with a confocal laser-scanning microscope (Zeiss LSM 510).

Statistical analysis. The data were presented as mean \pm SEM. Statistical difference was determined by paired or unpaired Student's $t$ test at a significance level of 0.05 .

\section{RESULTS}

\section{Intrinsic properties of native and mutated dopaminergic neurons}

To identify the dopaminergic neurons among a heterogeneous population of cells, we considered the electrophysiological param- eters already established as "typical" for these cells (Grace and Onn, 1989; Lacey et al., 1989: Johnson and North, 1992; Mercuri et al., 1995, 1997; Richards et al., 1997). In fact, we evaluated the presence of a strong hyperpolarization-activated inward current $\left(I_{\mathrm{h}}\right)$, the ability to fire spontaneously in a pacemaker manner, and the value of the resting membrane potential of the presumed dopaminergic neurons from both $+/+$ and homozygous $w v / w v$ mice. Hyperpolarizing voltage steps (Fig. $1 A$ ) from -60 to -120 $\mathrm{mV}\left(V_{\mathrm{h}}\right.$ of $\left.-40 \mathrm{mV}\right)$ evoked an inward current $\left(I_{\mathrm{h}}\right)$ in both $+/+$ and $w v / w v$ neurons. The mean current amplitudes, measured at -120 $\mathrm{mV}$, were $321 \pm 46 \mathrm{pA}(n=10)$ in $+/+$ and $490 \pm 46 \mathrm{pA}(n=16)$ (unpaired $t$ test, $p<0.05$ ) in $w v / w v$ neurons. Activation kinetics at $-120 \mathrm{mV}$ were $145 \pm 9 \mathrm{msec}$ in $+/+(n=10)$ and $116 \pm 8 \mathrm{msec}$ $(n=16)$ (unpaired $t$ test, $p<0.05$ ) in $w v / w v$ dopaminergic neurons, respectively. Under current-clamp recordings (Fig. $1 B$ ), depolarizing current steps elicited regularly firing action potentials, whereas hyperpolarizing pulses activated a characteristic "sag" potential in both $+/+(n=10)$ and $w v / w v(n=16)$ neurons. The mean resting membrane potential (Fig. $1 C$, left ) (holding potential at 0 current) was $-47.6 \pm 1.5 \mathrm{mV}$ in $+/+(n=17)$ and $-47.1 \pm 1.3 \mathrm{mV}$ in $w v / w v$ $(n=18)$ (unpaired $t$ test, $p=0.81)$ neurons. The mean values of the spontaneous firing (Fig. $1 C$, right) were $2.1 \pm 0.12 \mathrm{~Hz}(n=7)$ in $+/+$ and $2.4 \pm 0.2 \mathrm{~Hz}(n=15)$ (unpaired $t$ test, $p=0.35)$ in

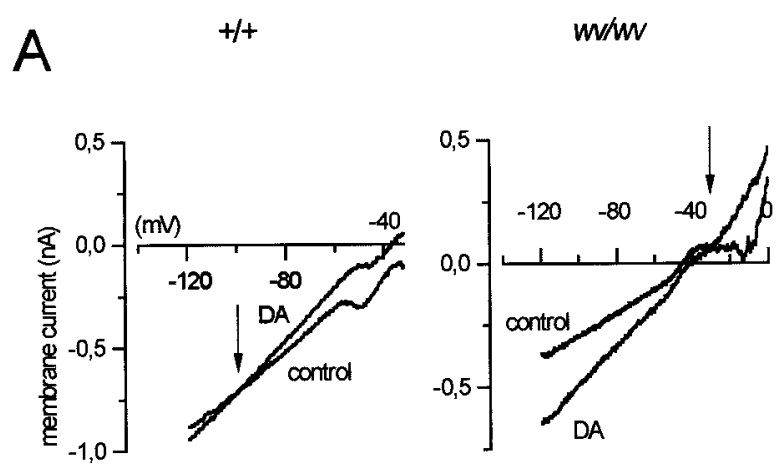

B
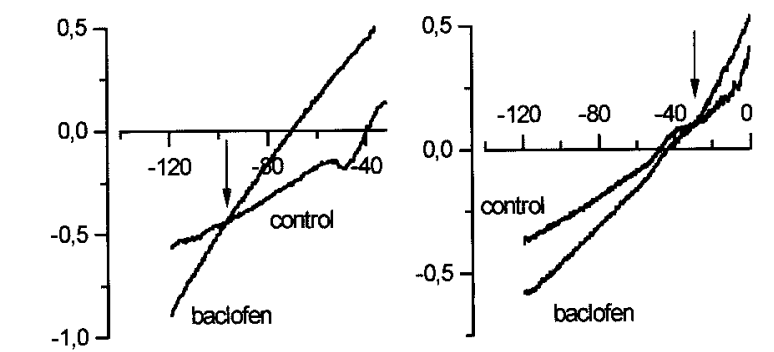

C

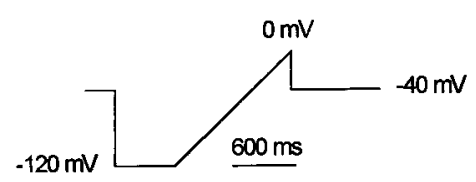

Figure 4. Properties of the DA- and baclofen-induced currents in $w v / w v$ neurons. $A$, Voltage ramps (from -120 to $0 \mathrm{mV}$ ) delivered in control condition and in the presence of DA revealed that the DA-induced (100 $\mu \mathrm{M})$ current reversed at $-86 \pm 6 \mathrm{mV}(n=4)$ in $+/+$ neurons (one cell is shown in the left , whereas it reversed at $-27 \pm 3.2 \mathrm{mV}(n=6)$ in $w v / w v$ neurons (one cell is shown in the right). $B$, The baclofen-activated $(10 \mu \mathrm{M})$ current reversed at negative potentials $(-87 \pm 3 \mathrm{mV}, n=4)$ in $+/+$ neurons (one cell is shown in the left), whereas it reversed at $-34.1 \pm 3.2$ $\mathrm{mV}(n=6)$ in $w v / w v$ neurons (one cell is shown in the right). The current traces of the $w v / w v$ neurons were recorded in the presence of TTX $(0.5 \mu \mathrm{M})$, tetraethylammonium chloride $(5 \mathrm{mM})$, and nifedipine $(10 \mu \mathrm{M})$ to reduce voltage-dependent sodium, potassium, and calcium conductances. $C$ shows the protocol used to induce the slow depolarizing ramps. 

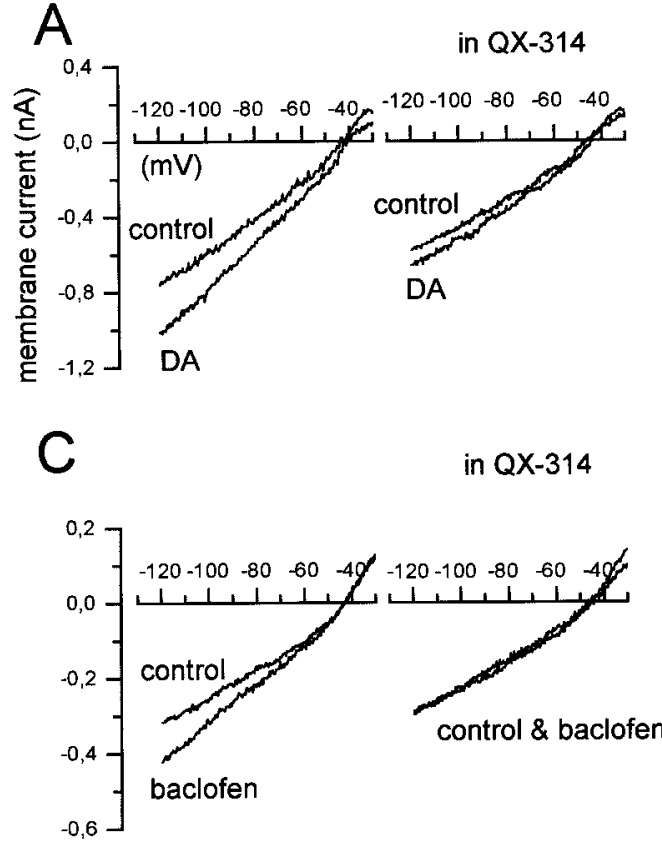

B

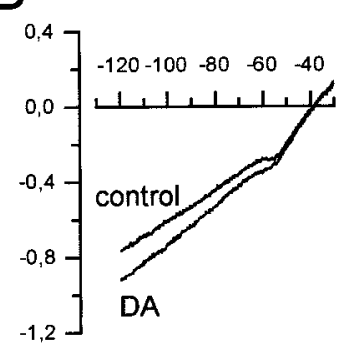

in ZD 7288

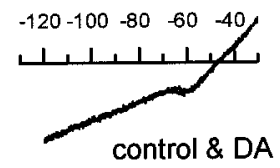

in $\mathrm{ZD} 7288$

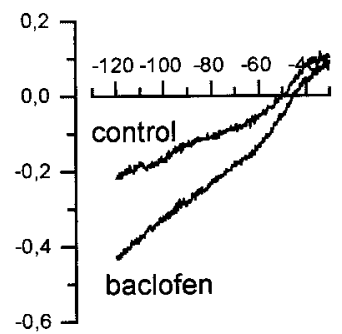

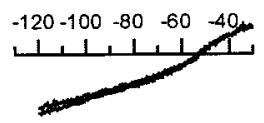

control \& baclofen

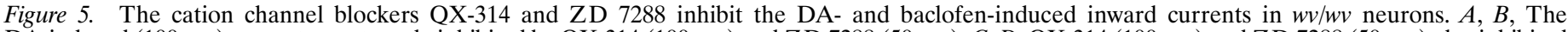

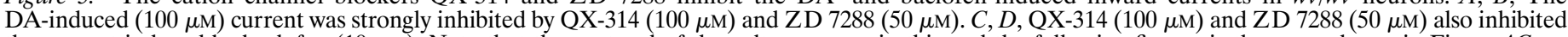

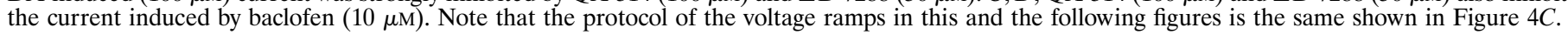

$w v / w v$ cells. The apparent input resistance (measured by a small 5 $\mathrm{mV}$ hyperpolarizing step) was $410 \pm 28(n=18)$ and $515 \pm 81(n=$ 7) $\mathrm{M} \Omega$ (unpaired $t$ test, $p=0.12$ ) in $+/+$ and $w v / w v$ cells, respectively.

Furthermore, we loaded some $w v / w v$ cells showing the electrophysiological properties delineated above with biocityn $(5 \mathrm{~mm})$, and we immunostained them with antibodies against TH. Nine of 10 neurons were TH-positive (Fig. 1D). Based on these observations, only neurons showing a pronounced $I_{\mathrm{h}}$ and a spontaneous pacemaker activity at rate of $\sim 2 \mathrm{~Hz}$ were considered to be dopaminergic and included in the present study.

\section{Activation of $D_{2}$ and $G A B A_{B}$ receptors mediates excitation of $w v / w v$ dopaminergic neurons}

It is well known that dopamine and GABA, by acting on $\mathrm{D}_{2}$ and $\mathrm{GABA}_{\mathrm{B}}$ receptors, inhibit the firing activity of dopaminergic neurons (Lacey et al., 1988). To test the effects of dopamine on $w v / w v$ dopaminergic neurons without perturbing the intracellular environment with the standard whole-cell configuration, we measured the rate of the spontaneous action potentials in cell-attached mode, in control condition and during the superfusion of dopamine (30 $\mu \mathrm{M})$ (Fig. 2A). Interestingly DA increased the firing frequency of $w v / w v$ neurons from $2.3 \pm 0.3(n=11)$ to $4.3 \pm 0.4(n=11) \mathrm{Hz}$ (paired $t$ test, $p<0.01$ ), whereas it abolished the spontaneous activity of the $+/+$ neurons $(n=4)$. In whole-cell current-clamp configuration (Fig. $2 B$ ), the $w v / w v$ dopaminergic neurons were depolarized by DA $(30 \mu \mathrm{M})$, and the number of the action potentials increased $(n=7)$. In contrast, DA $(30 \mu \mathrm{M})$ hyperpolarized the membrane and abolished the spontaneous activity of $+/+$ neurons $(n=4)$ (Lacey et al., 1988). Whole-cell voltage-clamp experiments (at $-40 \mathrm{mV}$ holding potential) showed that the excitatory effect of DA on $w v / w v$ neurons is attributable to the activation of an inward current $(58.3 \pm 13 \mathrm{pA}, n=7)$ (Fig. $2 C$ ). On the contrary, the inhibitory effect of DA in $+/+$ neurons is attributable to the activation of an outward current that is caused by the opening of GIRK channels (Lacey et al., 1988; Kim et al., 1997).

An excitation of $w v / w v$ dopaminergic neurons was also observed when they were exposed to the $\mathrm{GABA}_{\mathrm{B}}$ receptor agonist baclofen (Fig. 3). In fact, in cell-attached configuration (Fig. $3 A$ ), baclofen $(10 \mu \mathrm{M})$ increased the spontaneous activity of $w v / w v$ neurons from $2.8 \pm 0.4(n=11)$ to $5.5 \pm 0.5(n=11) \mathrm{Hz}$ (paired $t$ test, $p<0.01)$, whereas it depressed the spontaneous firing in $+/+$ neurons $(n=$ 4). In whole-cell current-clamp mode, baclofen mimicked the effects of DA, mediating a depolarization-excitation of $w v / w v$ neurons $(n=7)$ (Fig. $3 B)$ and a hyperpolarization of $+/+$ neurons $(n=4)$. In voltage-clamp recordings, baclofen $(10 \mu \mathrm{M})$ activated an inward current of $57.5 \pm 10.8 \mathrm{pA}(n=7)$ in $w v / w v$ neurons (Fig. $3 C$ ). Conversely, baclofen inhibited the $+/+$ dopaminergic neurons, activating a classical GIRK-mediated outward current $(n=4)$ (Lacey et al., 1988).

\section{Properties of the dopamine- and baclofen-induced inward current}

To characterize the $I-V$ relationships of the dopamine- and baclofen-induced inward currents, we performed voltage ramps over a wide range of potentials, between -120 and $0 \mathrm{mV}$ (Fig. $4 C$ ). The ramps were delivered in control condition and in the presence of DA $(100 \mu \mathrm{M})$ (Fig. $4 A)$ or baclofen $(10 \mu \mathrm{M})$ (Fig. $4 B)$. The currents activated by both agonists in $w v / w v$ neurons showed different characteristics compared with those induced in $+/+$ cells. Indeed, as expected for an increase of a pure potassium conductance (Lacey et al., 1988), the DA- and baclofen-induced currents crossed the control trace around $E_{\mathrm{K}}$ at $-86 \pm 6(n=4)$ and $-87 \pm$ $3(n=4) \mathrm{mV}$, respectively, in $+/+$ neurons. Instead, the DA- and baclofen-induced currents crossed the control trace at $-27 \pm 3.2$ $(n=6)$ and $-34 \pm 3.2(n=6) \mathrm{mV}$, respectively, in $w v / w v$ neurons. These values of reversal potential suggest that a cation current is involved in the neurotransmitter-mediated excitation of the $w v / w v$ dopaminergic neurons. Because the $I_{\mathrm{h}}$ is a mixed cationic current, we tested the possibility that both $\mathrm{D}_{2}$ and $\mathrm{GABA}_{\mathrm{B}}$ receptors could modulate $I_{\mathrm{h}}$ to produce excitation. In the presence of cesium (1-3 $\mathrm{mm}$ ), a known blocker of $I_{\mathrm{h}}$, the actions of dopamine and baclofen were not modified ( $n=3$; data not shown). Conversely, the antiarrhythmic drug ZD $7288(50 \mu \mathrm{M})$, which is also a potent inhibitor of $I_{\mathrm{h}}$, irreversibly depressed the DA-induced $(n=6)$ and baclofen-induced $(n=6)$ inward currents (Fig. $5 B, D)$. Furthermore, we tested a more classical cationic blocker, QX-314 $(100 \mu \mathrm{M})$, on the neurotransmitter-induced inward currents. As already reported in Xenopus oocytes expressing the wv GIRK2 (Kof uji et al., 1996), this drug inhibited the excitatory effects of DA (Figs. $5 A, 6 C$ ) $(n=7)$ and baclofen $(n=6)$ (Figs. $5 C, 6 C)$ on the dopaminergic $w v / w v$ cells without modifying the receptor-operated outward cur- 
rents in $+/+$ neurons (data not shown). Furthermore, QX-314 did not change the spontaneous activity and the membrane properties of the $w v / w v$ dopaminergic cells $(n=3$ of 3 cells tested; data not shown). The activation of $w v$ GIRK2 by dopamine and baclofen was inhibited by the $\mathrm{D}_{2}$ and $\mathrm{GABA}_{\mathrm{B}}$ receptor antagonists sulpiride and CGP 55845A (Fig. 6B). In fact, the mean amplitudes of the inward current activated by dopamine and baclofen at $-120 \mathrm{mV}$ in control conditions, in the presence of QX-314 $(100 \mu \mathrm{M})$, sulpiride $(3-10 \mu \mathrm{M})$, and CGP 55845A (250-500 nM), are shown in Figure $6 C$. The DA-induced current of $207 \pm 33 \mathrm{pA}(n=7)$ was significantly reduced to $111 \pm 13 \mathrm{pA}(n=7)$ (paired $t$ test, $p<0.05)$ in the presence of QX-314 and to $117 \pm 17 \mathrm{pA}(n=7)$ (paired $t$ test, $p<0.05)$ in the presence of sulpiride $(10 \mu \mathrm{M})$ (Fig. 6C, top).

The baclofen-induced current of $198 \pm 28 \mathrm{pA}(n=6)$ was significantly reduced to $63 \pm 15 \mathrm{nA}(n=6)$ (paired $t$ test, $p<0.01$ ) by QX-314 and to $21 \pm 8 \mathrm{pA}(n=6)$ (paired $t$ test, $p<0.01)$ by CGP 55845A (250 nM) (Fig. 6C, bottom).

\section{$D_{2}$ and $G A B A_{B}$ receptors activate $w v$ GIRK channels in a G-protein-dependent manner}

In heterologous expression systems, $w v$ GIRK2 channels not only loose the potassium selectivity but also become constitutively active, being unable to interact with the G-protein (Kofuji et al., 1996, Slesinger et al., 1996). In cells of the CNS, different gating properties of $w v$ GIRK2 have been reported; in fact, some neurons had no functional wv GIRK2 channels (Surmeier et al., 1996; Jarolimek et al., 1998), and others underwent a constitutive activation of GIRK2 (Rossi et al., 1998). To investigate the G-protein dependency of the receptor-operated $w v$ GIRK2, we dialyzed the cytoplasm with a nonhydrolizable GTP analog, GTP- $\gamma-\mathrm{S}(0.6 \mathrm{~mm})$. Before breaking the membrane patch for the whole-cell recordings, we tested the DA and baclofen sensitivity of the $w v / w v$ neurons by measuring their firing rate in cell-attached configuration. Both DA $(n=5)$ and baclofen $(n=5)$ increased the spontaneous firing of the $w v / w v$ neurons (Fig. $7 A$ ). Five to $10 \mathrm{~min}$ after the membrane rupture, a constitutive inward current developed and reached a plateau of $-74 \pm 22 \mathrm{pA}(n=5$; holding potential at $-40 \mathrm{mV})$. The mean amplitudes of DA- and baclofen-induced currents, at - 120
$\mathrm{mV}$, in $w v / w v$ cells loaded with the pipette solution containing GTP-Na $\mathrm{Na}_{3}$ (control) or GTP- $\gamma$-S were significantly different (Fig. $7 B)$. In fact, the DA-induced current of $204 \pm 30 \mathrm{pA}(n=10)$ in GTP-Na $-\mathrm{Na}_{3}$-loaded neurons was reduced to $38 \pm 14 \mathrm{pA}(n=5)$ (unpaired $t$ test, $p<0.05$ ) in GTP- $\gamma$-S-loaded neurons. The baclofen-induced current of $205 \pm 40 \mathrm{pA}(n=6)$ in GTP-Na loaded neurons was diminished to $57 \pm 10 \mathrm{pA}(n=5)$ (unpaired $t$ test, $p<0.05$ ) in GTP- $\gamma$-S-loaded cells. Moreover, we found that the inward current tonically activated by GTP- $\gamma$-S (Fig. 7C) was reduced in a reversible manner by QX-314 $(100 \mu \mathrm{M})(n=5)$ and irreversibly by ZD $7288(50 \mu \mathrm{M})(n=5)$. These results strongly suggest that the inward current induced by GTP- $\gamma-\mathrm{S}$ is the same as the one generated by DA and baclofen. On the other hand, whereas DA $(n=5)$ and baclofen $(n=5)$ excited the $w v / w v$ dopaminergic neurons in cell-attached configuration (Fig. 8A), the subsequent intracellular dialysis with the nonhydrolizable GDP analog GDP$\beta$-S $(0.6 \mathrm{~mm})$ prevented DA and baclofen effects within a few minutes after membrane rupture (Fig. $8 B$ ). In fact, the mean amplitudes of DA-induced current (at $-120 \mathrm{mV}$ ) of $204 \pm 30 \mathrm{pA}$ $(n=10)$ in GTP-Na - -loaded neurons was significantly reduced to $39 \pm 15 \mathrm{pA}(n=5)$ (unpaired $t$ test, $p<0.01)$ in GDP- $\beta$-S-loaded neurons. Furthermore, the baclofen-induced currents (at -120 $\mathrm{mV})$ of $205 \pm 40 \mathrm{pA}(n=6)$ in GTP-Na - loaded neurons was reduced to $21 \pm 19 \mathrm{pA}(n=5)$ (unpaired $t$ test, $p<0.01$ ) in GDP- $\beta$-S-loaded neurons.

\section{DISCUSSION}

The present study demonstrates that the $w v$ mutation reverses the functional effects (inhibition into excitation) mediated by activation of dopamine $\mathrm{D}_{2}$ and $\mathrm{GABA}_{\mathrm{B}}$ receptors in dopaminergic neurons of the ventral midbrain (identified physiologically and by TH immunoreactivity) and provides the first evidence of a $\mathrm{D}_{2-}$ and $\mathrm{GABA}_{\mathrm{B}}-$ mediated excitation in native neurons of the CNS.

\section{The membrane properties of $w v / w v$ dopaminergic} neurons are not affected by the mutation

There is a general agreement that the $w v$ GIRK2 looses selectivity for potassium ions. In fact, the permeability and gating properties
A
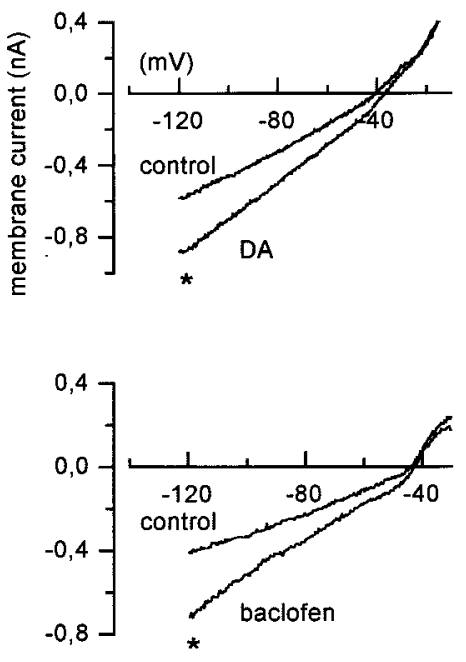

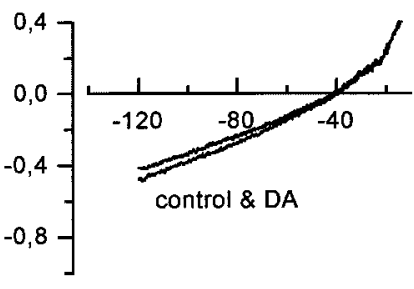

in CGP 55845A

B

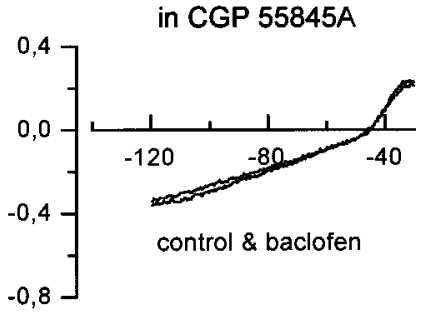

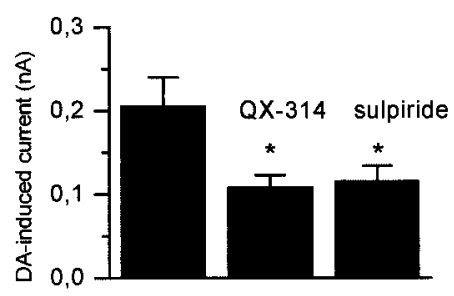

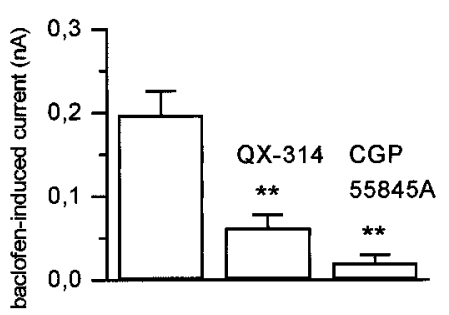

Figure 6. $\mathrm{D}_{2}$ and $\mathrm{GABA}_{\mathrm{B}}$ receptor antagonists reduce the DA- and baclofen-induced inward currents. $A$, The inward current induced by both agonists in $w v / w v$ dopaminergic neurons was inhibited by the presence of sulpiride $(10 \mu \mathrm{M} ; B$, top $)$ and CGP $55845 \mathrm{~A}(250 \mathrm{nM} ; B$, bottom $)$. $C$, The plots show the mean values of DA-induced (top, black columns) and baclofen-induced (bottom, white columns) inward currents at the points indicated by asterisks in $A$ $(-120 \mathrm{mV})$. The DA-induced inward current was $207 \pm 33 \mathrm{pA}(n=7$; left bar $)$ and was significantly reduced by QX-314 (100 $\mu \mathrm{M})$ to $111 \pm 13 \mathrm{pA}$ (paired $t$ test, $p<0.05$; middle bar) and by sulpiride $(10 \mu \mathrm{M})$ to $117 \pm 17 \mathrm{pA}$ (paired $t$ test, $p<0.05$; right bar). The baclofen-induced inward current of $198 \pm$ $28 \mathrm{pA}(n=6$; left bar) was significantly reduced by QX-314 (100 $\mu \mathrm{M})$ to $63 \pm 15$ (paired $t$ test, $p<0.01$; middle bar $)$ and by CGP $55845 \mathrm{~A}(250 \mathrm{nM})$ to $21 \pm$ 8 pA (paired $t$ test, $p<0.01$; right bar). 
A

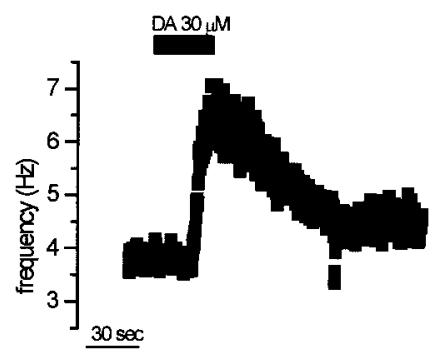

Figure 7. $\quad \mathrm{D}_{2}$ and $\mathrm{GABA}_{\mathrm{B}}$ receptors couple to $w v$ GIRK2 in a G-protein-dependent manner. $A$, Recordings of the spontaneous firing of two $w v / w v$ neurons in cell-attached configuration with a pipette solution containing the GTP analog GTP- $\gamma$-S (0.6 mM). Note that both DA (left) and baclofen (right) induced an increase of the spontaneous firing before the rupture of the membrane patches. $B$, The black columns show the amplitude of the DA-induced current $($ at $-120 \mathrm{mV})(204 \pm 30 \mathrm{pA}, n=10)$ in control conditions and during the dialysis with GTP- $\gamma$-S $(38 \pm 14$ $\mathrm{pA}, n=5)(p<0.05$, unpaired data). The white columns show the amplitude of the baclofen-induced current (at $-120 \mathrm{mV})(205 \pm 40 \mathrm{pA}, n=6)$ in control condition and during the intracellular dialysis with GTP- $\gamma-\mathrm{S}(57 \pm 10$, $n=5)(p<0.05$, unpaired data). $C$, GTP- $\gamma$-S induced a tonic inward current that was reversibly blocked by QX314 and irreversibly inhibited by ZD 7288. Note that, under this condition, the response to DA application was not observed.
$B$

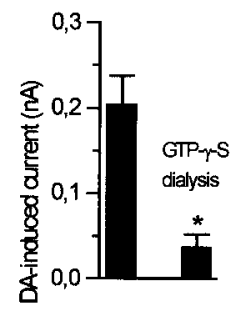

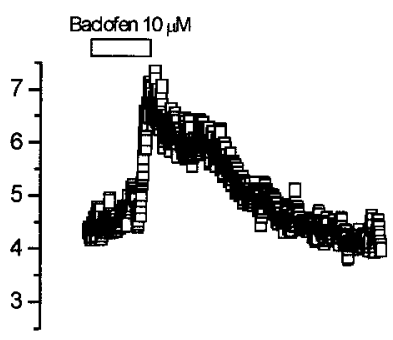

C

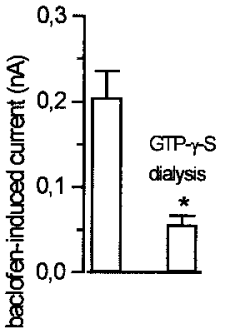

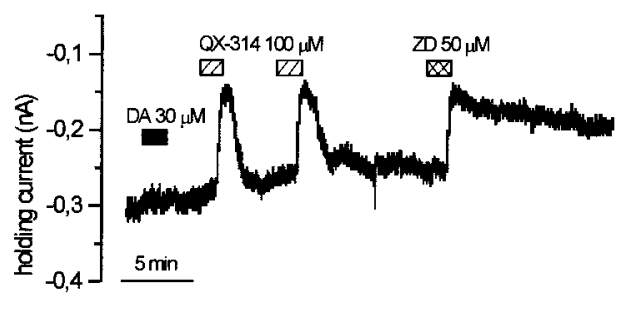

of the $w v$ GIRK2 have been extensively investigated in heterologous expression systems in which it has been shown that the mutated channel becomes permeable to sodium (Navarro et al., 1996; Slesinger et al., 1996) and eventually to calcium ions (Silverman et al., 1996; Tucker et al., 1996). In addition, this channel appears to be constitutively opened (Kofuji et al., 1996). Consequently, there is a leakage entry of sodium into the cells that can be reduced by channel blockers such as QX-314, MK-801, and verapamil. A constitutive activation of the $w v$ GIRK2 was also observed in cultured cerebellar granule cells (Kofuji et al., 1996) and in putative granule cells in the postmigratory position in $w v / w v$ cerebellar slices (Rossi et al., 1998). A similar constitutively opened $w v$ GIRK2 conductance, sensitive to QX-314, has been described recently in substantia nigra $w v / w v$ neurons (Liss et al., 1999). In fact, the dopaminergic cells were found to be tonically depolarized, having no pacemaker activity. Among the surviving cells within the substantia nigra compacta (SNc) of the $w v / w v$ mice, we found a cell population whose resting potential, apparent input resistance, and spontaneous firing discharge were indistinguishable from those of the dopaminergic neurons recorded in $+/+$ mice. Thus, our results strongly suggest that the mutated GIRK2 channels do not regulate the resting properties of native $w v / w v$ dopaminergic neurons. This is supported by the following arguments: (1) a depolarized resting membrane potential, a decrease in input resistance, and a loss of spontaneous pacemaker activity should be expected if a tonic $w v$ inward conductance is present; and (2) the spontaneous firing activity should be affected by the $w v$ GIRK2 blocker QX-314 if the channel is operative during the resting state of the neurons.

\section{The membrane responses of dopaminergic neurons to} dopamine and GABA are modified by the $w \boldsymbol{v}$ mutation

Among the characteristics that identify the dopaminergic neurons in the ventral midbrain, an inhibitory response to dopamine is an important criterion (Mercuri et al., 1992; White, 1996). In $w v / w v$, mice we found neurons displaying spontaneous firing, resting membrane potential, apparent input resistance, and firing rate comparable with the ones recorded in wild animals. A more pronounced $I_{\mathrm{h}}$ (Mercuri et al., 1995) was also found in $w v / w v$ cells. This might depend on either compensatory changes of the hyperpolarizationactivated channels or a reduced apparent inhibition caused by DA and GABA (Watts et al., 1996). Interestingly, the cellular responses to dopamine and the $\mathrm{GABA}_{\mathrm{B}}$ agonist baclofen were opposite to those observed in control animals. In fact, both dopamine and baclofen, instead of inhibiting the $w v / w v$ dopaminergic cells by activating a G-protein-dependent outward current (Lacey et al., 1988; Kim et al., 1997), caused an excitation that was generated by an inward current. The obtained null potential (approximately -30 $\mathrm{mV}$ ) and the sensitivity of this current to cationic channel blockers support the hypothesis that DA and baclofen activate wv GIRK2 channels, which are permeable to sodium and potassium ions (Kofuji et al., 1996). The loss of selectivity of the $w v$ GIRK2 to potassium ions has been already demonstrated in other systems

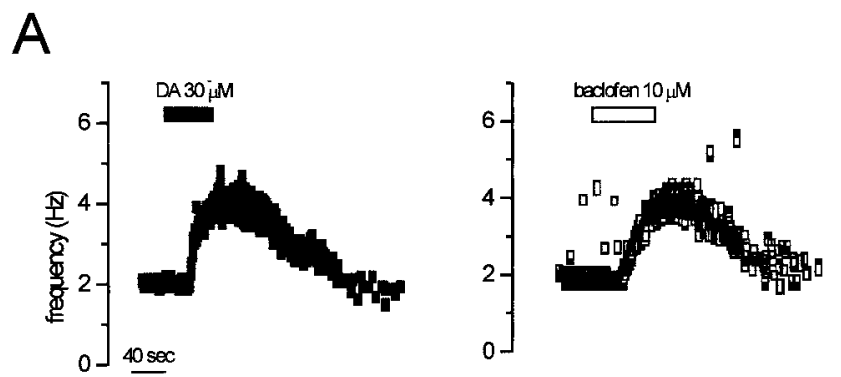

B
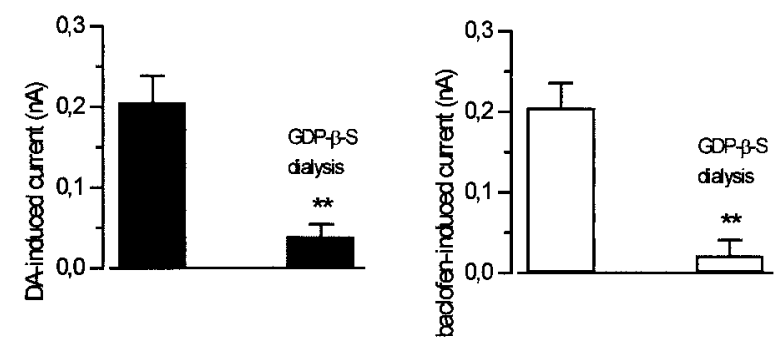

Figure 8. GDP- $\beta$-S prevents the DA- and baclofen-induced inward currents. $A$, Cell-attached recordings of two $w v / w v$ neurons with a pipette containing the GDP analog GDP- $\beta$-S $(0.6 \mathrm{~mm})$ showing the increase of the spontaneous firing caused by DA and baclofen. B, Left, black columns, In whole-cell configuration, the DA-induced current (at $-120 \mathrm{mV}$ ) was $204 \pm$ $30 \mathrm{pA}(n=10)$ and was significantly reduced by GDP- $\beta$-S to $39 \pm 15 \mathrm{pA}$ $(n=5, p<0.01$, unpaired data). Right, white columns, The baclofeninduced current (at $-120 \mathrm{mV})$ was $205 \pm 40 \mathrm{pA}(n=6)$ and was significantly reduced by GDP- $\beta$-S to $21 \pm 19 \mathrm{pA}(n=5, p<0.01$, unpaired data). 
expressing the homomeric $w v$ GIRK2 (Kofuji et al., 1996; Navarro et al., 1996; Slesinger et al., 1996). Nevertheless, it is worth mentioning that the responses to baclofen were lost in $w v / w v$ hippocampal (Jarolimek et al., 1998) and cerebellar granule cells (Slesinger et al., 1997). The lack of neurotransmitter action in these cells without a gain of function might depend on the compensatory effect of other GIRK family members (Hou et al., 1999).

It is noteworthy that the neurotransmitter-operated $w v$ GIRK2 is not only sensitive to QX-314 but also to the bradycardic agent ZD 7288, a blocker of the mixed sodium/potassium current $I_{\mathrm{h}}$. This observation rises the possibility that dopamine and baclofen might modulate the $I_{\mathrm{h}}$ in the $w v / w v$ dopaminergic cells. However, this is not the case because, when the $I_{\mathrm{h}}$ was blocked by extracellular cesium (Mercuri et al., 1995), dopamine and baclofen still induced an inward current in the $w v / w v$ dopaminergic cells. Moreover, it appears that the inward current caused by dopamine and baclofen is attributable to the activation of $D_{2}$ and $G_{A B A}$ receptors, respectively. In fact, antagonists such as sulpiride $\left(\mathrm{D}_{2}\right)$ and CGP $55845 \mathrm{~A},\left(\mathrm{GABA}_{\mathrm{B}}\right)$ specifically inhibited the effects of these neurotransmitters. The observation that the DA-induced inward current was not completely blocked by sulpiride and QX 314 suggests that this catecholamine might have additional non-D2, non-GIRK2 actions. Further experiments will be necessary to address this problem.

An additional important conclusion of our results is that the neurotransmitter activation of the mutated GIRK2 channel uses, as in control condition, a G-protein. Indeed, intracellular dialysis with GTP- $\gamma-S$ or GDP- $\beta$-S prevented the neurotransmitter-mediated inward currents. In agreement with the involvement of a G-protein in the activation of the $w v$ GIRK2, the intracellular dialysis of the nonhydrolizable analog of GTP, GTP- $\gamma$-S, caused a sustained inward current, which determined membrane depolarization, loss of spontaneous activity, and occluded DA- and baclofen-induced responses. The fact that the inward current caused by GTP- $\gamma-\mathrm{S}$ was reversibly inhibited by QX-314 and irreversibly blocked by ZD 7288 also suggests that it is produced by G-protein-regulated opening of the $w v$ GIRK2 channels.

\section{Conclusions}

In the present paper, we provide evidence that $w v$ GIRK2 are specifically operated by $\mathrm{D}_{2}$ and $\mathrm{GABA}_{\mathrm{B}}$ receptors in a G-proteindependent manner to induce depolarization of native dopaminergic neurons. It is likely that the aberrant receptor-activated cationic entry throughout the $w v$ GIRK2 could result in activity-dependent cell death, attributable to severe depolarization and sodium/calcium accumulation. Moreover, the presence of synaptic excitation instead of a $\mathrm{K}^{+}$-dependent inhibition failing to counterbalance the depolarizing drive sustained by the release of excitatory amino acids (Jensen et al., 1999) certainly contributes to initiate sodium/ calcium-dependent intracellular processes, which lead to degeneration of $w v / w v$ dopaminergic cells (Bertolino and Llinas, 1992; Choi, 1995; Verney et al., 1995; Oo et al., 1996). Although the mechanisms producing neuronal degeneration are not known yet, our results suggest that they can be related to the tone of dopamine and GABA in the ventral mesencephalon that regulates a deviate function of the $w v$ GIRK2 channels (Liao et al., 1996). In addition, the mutation of the GIRK2 channel, by reversing the functional effects of dopamine, would not only impair the autoreceptormediated control of neurotransmitter release but also enhance, with a feedforward mechanism, the level of this catecholamine in the terminal fields. The altered behavior of the spared dopaminergic cells, as a consequence of DA autoreceptors stimulation, could account for the enhanced fractional release of dopamine in the striatum of $w v / w v$ mice (Richter et al., 1995). Thus, the observed hyperactivity of the $w v / w v$ mice could, at least in part, depend on the dysfunction of the autoreceptor-mediated control of the dopaminergic neurons.

\section{REFERENCES}

Bayer SA, Willis KV, Triarhou LC, Verina T, Thomas JD, Ghetti B (1995) Selective vulnerability of late-generated dopaminergic neurones of the substantia nigra in weaver mutant mice. Proc Natl Acad Sci USA 92:9137-9140.

Bertolino M, Llinas RR (1992) The central role of voltage-activated and receptor-operated calcium channels in neuronal cells. Annu Rev Pharmacol Toxicol 32:399-421.

Choi DW (1995) Calcium: still center-stage in hypoxic-ischemic neuronal death. Trends Neurosci 18:58-60.

Grace A, Onn SP (1989) Morphology and electrophysiological properties of immunocytochemically identified rat dopamine neurones recorded in vitro. J Neurosci 9:3463-3481.

Gupta AM, Felten DL, Ghetti B (1987) Selective loss of monoaminergic neurones in the weaver mutant mice: an immunocytochemical study. Brain Res 402:379-382.

Hille B (1992) Ionic channels of excitable membranes. Ed 2. Sunderland, MA: Sinauer.

Hou P, Yan S, Tang W, Nelson DJ (1999) The inwardly rectifying $\mathrm{K}^{+}$ channel submit GIRK1 rescues the GIRK2 weaver phenotype. J Neurosci 19:8327-8336.

Inanobe A, Yoshimoto Y, Horio Y, Morishige KI, Hibino H, Matsumoto S, Tokunaga Y, Maeda T, Hata Y, Takai Y, Kurachi Y (1999) Characterization of G-protein-gated $\mathrm{K}^{+}$channels composed of Kir3.2 subunits in dopaminergic neurons of the substantia nigra. J Neurosci 19:1006-1017.

Jan LY, Jan YN (1994) Potassium channels and their evolving gates. Nature 371:119-122.

Jarolimek W, Bäurle J, Misgeld U (1998) Pore mutation in a G-proteingated inwardly rectifying $\mathrm{K}^{+}$channel subunit causes loss of $\mathrm{K}^{+}$dependent inhibition in weaver hippocampus. J Neurosci 18:4001-4007.

Jensen P, Surmeier DJ, Goldowitz D (1999) Rescue of cerebellar granule cells from death in weaver NR1 double mutants. J Neurosci 19:7991-7998.

Johnson SW, North RA (1992) Two types of neurone in the rat ventral tegmental area and their synaptic inputs. J Physiol (Lond) 450:455-468.

Kim KM, Nakajima S, Nakajima Y (1997) Dopamine and GABA receptors in cultured substantia nigra neurons: correlation of electrophysiology and immunocytochemistry. Neuroscience 78:759-769.

Kofuji P, Hofer M, Millen KJ, Millonig JH, Davidson N, Lester HA, Hatten ME (1996) Functional analysis of the weaver mutant GIRK2 K ${ }^{+}$ channel and rescue of weaver granule cells. Neuron 16:941-952.

Lacey MG, Mercuri NB, North RA (1988) On the potassium conductance increase activated by $\mathrm{GABA}_{\mathrm{B}}$ and $\mathrm{D}_{2}$ receptors in rat substantia nigra neurones. J Physiol (Lond) 401:437-453.

Lacey MG, Mercuri NB, North RA (1989) Two cell types in rat substantia nigra zona compacta distinguished by membrane properties and the actions of dopamine and opioids. J Neurosci 9:1233-1241.

Liao YJ, Jan YN, Jan LJ (1996) Heteromultimerization of G-proteingated inwardly rectifying $\mathrm{K}^{+}$channel proteins GIRK1 and GIRK2 and their altered expression in weaver brain. J Neurosci 16:7137-7150.

Liss B, Neu A, Roeper J (1999) The weaver mouse gain-of-function phenotype of dopaminergic neurons is determined by coactivation of $w v$ GIRK2 and K-ATP channels. J Neurosci 19:8839-8848.

Mercuri NB, Calabresi P, Bernardi G (1992) The electrophysiological actions of dopamine and dopaminergic drugs on neurones of the substantia nigra pars compacta and ventral tegmental area. Life Sci $51: 711-718$.

Mercuri NB, Bonci A, Johnson SW, Stratta F, Calabresi P, Bernardi G (1994) Effects of anoxia on rat midbrain dopamine neurons. J Neurophysiol 71:1165-1173.

Mercuri NB, Bonci A, Calabresi P, Stefani A, Bernardi G (1995) Properties of the hyperpolarization-activated cation current $\left(\mathrm{I}_{h}\right)$ in rat midbrain dopaminergic neurons. Eur J Neurosci 7:462-469.

Mercuri NB, Saiardi A, Bonci A, Picetti R, Calabresi P, Bernardi G, Borrelli E (1997) Loss of autoreceptor function in dopaminergic neurons from dopamine D2 receptor deficient mice. Neuroscience 79:323-327.

Murer G, Adelbrecht C, Lauritzen I, Lesage F, Lazdunski M, Agid Y, Raisman-Vozari R (1997) An immunocytochemical study on the distribution of two G-protein-gated inward rectifier potassium channels (GIRK2 and GIRK4) in the adult rat brain. Neuroscience 80:345-357.

Navarro B, Kennedy ME, Velimirovic B, Bhat D, Peterson AS, Clapham DE (1996) Nonselective and $\mathrm{G}_{\beta \gamma}$-insensitive weaver $\mathrm{K}^{+}$channels. Science 272:1950-1953.

North RA (1989) Drug receptors and the inhibition of nerve cells. Twelfth Gaddum memorial lecture. Br J Pharmacol 98:13-28.

Oo TF, Blazeski R, Harrison SM, Henchcliffe C, Mason CA, Roffler-Tarlov SK, Burke RE (1996) Neuron death in the substantia nigra of weaver mouse occurs late in development and is not apoptotic. J Neurosci 16:6134-6145.

Patil N, Cox DR, Bhat D, Faham M, Myers RM, Peterson AS (1995) A potassium channel mutation in weaver mice implicates membrane excitability in granule cell differentiation. Nat Genet 11:126-129.

Rakic R, Sidman RL (1973) Sequence of developmental abnormalities leading to granule cell deficit in cerebellar cortex of weaver mutant mice. J Comp Neurol 152:103-132. 
Richards CD, Shiroyama T, Kitai ST (1997) Electrophysiological and immunocytochemical characterization of GABA and dopamine neurons in the substantia nigra of the rat. Neuroscience 80:545-557.

Richter JA, Bare DJ, Yu H, Ghetti B, Simon JR (1995) Dopamine transporter-dependent and -independent endogenous dopamine release from weaver mouse striatum in vitro. J Neurochem 64:191-198.

Roffler-Tarlov S, Graybiel AM (1984) Weaver mutant has differential effects on the dopamine-containing innervation of the limbic and nonlimbic striatum. Nature 307:62-66.

Rossi P, De Filippi G, Armano S, Taglietti V, D’Angelo E (1998) The weaver mutation causes a loss of inward rectifier current regulation in premigratory granule cells of the mouse cerebellum. J Neurosci 18:3537-3547.

Schmidt MJ, Sawyer BD, Perry KW, Foreman MM, Ghetti B (1982) Dopamine deficiency in the weaver mutant mouse. J Neurosci 2:376-380.

Silverman SK, Kof uji P, Dougherty DA, Davidson N, Lester HA (1996) A rigenerative link in the ionic fluxes through the weaver potassium channel underlies the pathophysiology of the mutation. Proc Natl Acad Sci USA 93:15429-15434.

Simon JR, Ghetti B (1994) The weaver mutant mouse as a model of nigrostriatal dysfunction. Mol Neurobiol 9:183-189.

Slesinger PA, Patil N, Liao YJ, Jan YN, Jan LY, Cox DR (1996) Functional effects of the mouse weaver mutation on G-protein-gated inwardly rectifying $\mathrm{K}^{+}$channels. Neuron 16:321-331.

Slesinger PA, Stoffel M, Jan YN, Jan LY (1997) Defective gammaaminobutyric acid type $\mathrm{B}$ receptor-activated inwardly rectifying $\mathrm{K}+$ currents in cerebellar granule cells isolated from weaver and Girk2 null mutant mice. Proc Natl Acad Sci USA 94:12210-12217.
Smith III MW, Cooper TR, Joh TH, Smith DE (1990) Cell loss and class distribution of TH-I cells in the substantia nigra of the neurological mutant, weaver. Brain Res 510:242-250.

Sodickson DL, Bean BP (1998) Neurotransmitter activation of inwardly rectifying potassium current in dissociated hippocampal CA3 neurons: interactions among multiple receptors. J Neurosci 18:8153-8162.

Surmeier DJ, Merlmestein PG, Goldowitz D (1996) The weaver mutation of GIRK2 results in a loss of inwardly rectifying $\mathrm{K}^{+}$current in cerebellar granule cells. Proc Natl Acad Sci USA 93:11191-11195.

Tong Y, Wei J, Zhang S, Strong JA, Dlouhy SR, Hodes ME, Ghetti B, Yu $\mathrm{L}$ (1996) The weaver mutation changes the ion selectivity of the affected inwardly rectifying potassium channel GIRK2. FEBS Lett 390:63-68.

Triarhou LC, Norton J, Ghetti B (1988) Mesencephalic dopamine cell deficit involves areas A8, A9 and A10 in weaver mice. Exp Brain Res 70:256-265.

Tucker SJ, Pessia M, Moorhouse AJ, Gribble F, Ashcroft FM, Maylie J, Adelman JP (1996) Heteromeric channel formation and $\mathrm{Ca}^{2+}$-free media reduce the toxic effect of the weaver Kir 3.2 allele. FEBS Lett 390:253-257.

Verney C, Febvret-Muzerelle A, Gaspar P (1995) Early postnatal changes of the dopaminergic mesencephalic neurons in the weaver mutant mouse. Brain Res Dev Brain Res 89:115-119.

Watts AE, Williams JT, Henderson G (1996) Baclofen inhibition of the hyperpolarization-activated cation current, Ih, in rat substantia nigra zona compacta neurons may be secondary to potassium current activation. J Neurophysiol 76:2262-2270.

White FJ (1996) Synaptic regulation of mesocorticolimbic dopamine neurons. Annu Rev Neurosci 19:405-436. 